\title{
Ineke Phaf-Rheinberger (ed.) El lenguaje-nación y la poética del acriollamiento. Una conversación entre Kamau Brathwaite y Édouard Glissant ${ }^{1}$
}

\author{
Traducción y notas de la Dra. Carolina Benavente Morales²
}

Brathwaite: Ya que el punto de partida de esta discusión es el lenguaje-nación $n^{3}$, intentaré explicar a qué se parece. En primer lugar, esta noción expresa la experiencia de un pueblo oprimido que siempre ha sido criticado y denigrado por el establishment debido a su estatus. El lenguaje-nación no se enseña en las escuelas; no se considera que sea una versión respetable del discurso y la literatura. El único lugar del Caribe anglófono donde puede ser escuchado públicamente es en la radio, es decir, en los avisos comerciales y en las canciones. Esto significa que, al

Este texto es la transcripción de la conversación que Kamau Brathwaite y Édouard Glissant sostuvieron entre el 21 y el 22 de marzo de 1991 en el Departamento de Español y Portugués de la Universidad de Maryland, EEUU. La conversación fue editada por Ineke Phaf-Rheinberger a partir del registro original en video y luego fue revisada por ambos autores. Esta información está contenida en una nota de la segunda edición de este texto. Todas las notas restantes son de la traductora. La versión original en inglés de este texto ha sido publicada en dos ocasiones. La primera de ellas como: Brathwaite, Kamau y Édouard Glissant (1996). "A dialogue. Nation language and poetics of creolization". En: Phaf-Rheinberger, Ineke, ed. Presencia criolla en el Caribe y América Latina. Creole Presence in the Caribbean and Latin America. Frankfurt am Main: Vervuert / Iberoamericana. 19-42. La segunda como: Phaf-Rheinberger, Ineke, ed. (2005). “Anexo 2: Nation language and poetics of creolization. A conversation between Kamau Brathwaite and Édouard Glissant". En: Phaf Rheinberger, ed. Memorias de la fragmentación. Tierra de libertad y paisajes del Caribe. Berlin: WVB. 115-130. No hay prácticamente diferencias entre estas ediciones, con excepción del título. Me baso en la segunda edición, pero ocupando las cursivas ocupadas en el título de la primera. Estas cursivas, aplicadas a "Nation Language" y "Poetics of creolization", son utilizadas en el cuerpo del texto de la segunda edición.

2 Dra. En Estudios Americanos, USACH. e-mail: cbenavem@gmail.com.

Agradezco la ayuda brindada por Rémy Amezcua y en particular por Patricio Tapia en la traducción de algunos pasajes especialmente controversiales.

3 La expresión original en inglés ocupada por Brathwaite es "Nation Language". En inglés no se distingue entre lengua y lenguaje, pero aunque Brathwaite muchas veces se refiera a la lengua, el sentido de la expresión trasciende la esfera verbal para abarcar otros recursos comunicativos, motivo por el cual traduzco esta expresión como "lenguaje-nación". Sigo en esto asimismo una sugerencia de Ineke Phaf-Rheinberger, quien me señala que "todo elemento lingüístico que une al Caribe es 'lenguaje" y me propone la expresión utilizada finalmente en lugar de "lenguaje de la nación". 
menos de manera semi-oficial, este lenguaje goza hoy en día de reconocimiento; que a través de él puede llegarse a la masa del pueblo. También se le puede escuchar en el teatro, pues en el drama resulta necesario para representar la lengua de la gente. Esta área de experiencia y de expresión que es el lenguaje-nación siempre nos ha acompañado, pues ha sido uno de nuestros mayores recursos. Lo trágico es que, al igual que tantas otras cosas, este recurso fundamental ha sido marginado.

Permítanme ejemplificarles cómo suena. Cuando la gente dice "deja que el agua de los ojos bese la luz de tus pestañas"4, "el agua de los ojos" significa "lágrimas" y "la luz de tus pestañas" describe el efecto que tienen las lágrimas sobre las pestañas de los ojos. En un inglés estándar decimos "veo tus ojos brillar mientras Iloras" o algo similar. De hecho, la expresión "el agua de los ojos" proviene de una traducción del kwa, que es una lengua $a \mathrm{ka}^{5}$ donde no existe un verbo específico para "Ilorar". Es decir, un adjetivo aquí se utiliza como un verbo, transformando la sintaxis. Esta sintaxis es interesante en sí, pero todavía no hemos sido capaces de estandarizarla.

Otro ejemplo es "haga el dumplin ${ }^{6}$ bom tu panza"7. Aquí estamos utilizando un montón de explosivos. "Haga" por "haz" ${ }^{\prime 8}$, "dumplin", que es un alimento que comemos por montones y al que le damos forma de albóndiga. Si el "dumplin" estalla en tu panza, significa que golpeará tu estómago y que lo hará con fuerza, es decir, que creará una fuerza dentro de ti que te producirá cierta pesantez. Hay también un encantador proverbio antiguo: "El ave ñam cucarachas en la corte de los reyes" ${ }^{9}$. Nuevamente "ñam" proviene del África occidental, es el verbo para "comer" en numerosas lenguas africanas y ha sido transferido al Caribe, donde es usado de la misma manera. Pero esta forma decorativa también se ocupa para mostrar que la corte inglesa de los reyes es un concepto extranjero yuxtapuesto a una expresión africana. Otro ejemplo es "el sonido del grillo se desliza sigiloso como las estrellas"10. Significa que el sonido de los grillos está deslizándose sigilosamente entre la hierba y que se mueve así, lentamente, en la noche y al igual que ella.

El lenguaje-nación no es ni un dialecto ni un pidgin ni una lengua vernácula, pese a que tal vez se base en estos elementos. A diferencia del

\footnotetext{
"Let the eyewater kiss the light of your lashes".

Se refiere Brathwaite a una lengua africana.

"Bola de masa hervida para servir con guiso", definición del Collins English Dictionnary Online.

"Mek dumplin bom your belly".

"'Mek' for 'Make"'.

"Fowl nyam cockroach in the court of kings".

"Cricket sound creep like Stars".
} 
dialecto, es decir, entendiendo este término tal como se usa en el Caribe, asociándolo a la idea de lo roto, lo sub-estándar, lo estúpido, ignorante, no importante o marginal, el lenguaje-nación implica un cosmos-lengua por derecho propio. Implica una energía-lenguaje que, al transportar la memoria y el bagaje de los ancestros, incorpora la sabiduría enriquecedora (la reverberación) del pro/verbio, la itálica y la nomenclatura, donde el nombre de las cosas equivale a su sonido, a su canto, a su profundidad o bien participa de ellos. Por sobre todo, a través del conjunto de sus elementos, tanto los antiguos como los modernos (demoníacos, mágicamente surreales, vuduistas), el lenguaje-nación siempre mira hacia el futuro de la nación / la lengua / la cultura. La Fola de Lamming ${ }^{11}$, el kumina de Miss Queenie, el limbo de EKB, Divina Trace ${ }^{12}$, de Bob Antoni, Beloved ${ }^{13}$, de Toni Morrison, Swim around Barbados de Julian Hunte ("mar no tener puerta trasera"; "panza llena no temer viento"; "Dios no amar feos"14). Es parte de la expresión de nuestro pueblo, pero no se le ha permitido formar parte central de nuestra cultura oficial. Forcejeamos con ella, es decir, muchas veces la usamos de manera consciente, pero al mismo tiempo la mantenemos sumergida.

Quiero darle un ejemplo personal acerca de lo difícil que fue alcanzar este concepto de la realidad. Yo nací en Barbados, que es una isla de coral muy pequeña, la más oriental de todas las islas caribeñas. El Caribe hoy es un destino turístico, un arco de 2.000 millas $^{15}$, un encantador arco de unas 2.000 islas, para el caso, que se extiende desde la punta de Florida hacia la costa sudamericana. Sus cumbres son una cordillera de montañas hundidas que, hace un millón de años atrás, formaron una gran espiral angular hacia el este a partir de las Américas, desde las Rocallosas hacia la Cordillera de América central y hasta los alucinantes Andes. Somos perpendiculares a esta formación y, debido a ello, fuimos más frágiles, pues quedamos más expuestos a las presiones de la deslizante curva del movimiento. Y es así como colapsamos hacia el océano, originando una catástrofe cuya memoria está hundida y dejando únicamente las cumbres sumergidas de estas memorias volcánicas, las islas del Caribe. Tengo la impresión de que, aún hoy, un millón de años después, seguimos escuchando el eco de aquella catástrofe y que gran parte de nuestro trabajo se relaciona con esa memoria. Hemos en cierto modo

11 Brathwaite se refiere al escritor caribeño Georges Lamming (Barbados).

12 "La huella de Divina". Esta novela de Robert Antoni (Trinidad / EEUU), publicada originalmente en 1991, aún no ha sido traducida al español.

13 "Amada". Beloved, novela de la Premio Nóbel 1993 Toni Morrison (EEUU), fue publicada originalmente en 1987. El título es el nombre de la protagonista, motivo por el cual sus traducciones al español lo conservan en inglés: Morrison, Toni (1993). Beloved. Barcelona: Ediciones B; Morrison, Toni (2004). Beloved. Barcelona: Mondadori - Debolsillo.

14 "Sea doan have back door; Full belly na fraid a wind; God doan love ugly; She delight in the fritter of de finder-dem".

$15 \quad 3.218 \mathrm{~km}$. 
perdido el sentido del continente, el sentido de la totalidad, y nos hemos convertido en agujeros en el océano. Como pueblo nos dirigíamos hacia Atlantis en el océano Atlántico y quedamos atrapados como tortugas ciegas en aquel mar.

Desde luego, mientras crecía en esa pequeña isla de Barbados, yo sólo tenía una conciencia difusa de todo esto. Solía caminar todo el día a lo largo de la playa, creciendo, lanzando piedras hacia el océano y escuchando el sonido de aquel mar, de aquel poderoso océano, de aquel sentido de la distancia en una isla muy pequeña de apenas 144 millas cuadradas ${ }^{16}$. Mi sentido del espacio y de la distancia, por ende, tuvo que venir del océano y del cielo. Tuve la sensación de que en algún lugar allá afuera estaba el génesis del Caribe, la respuesta a lo que yo esperaba poder crear como artista, un génesis que es realmente donde todo arte comienza.

Mientras caminaba a lo largo de esa playa me di cuenta de que la historia que me había sido legada no me permitía heredar de ningún sentido natural del génesis. Más bien, me permitió heredar de un sentido del genocidio, lo que es muy diferente del génesis y, fundamentalmente, es su opuesto, porque la gente que hereda ese paisaje recogiendo el eco de aquella catástrofe ha sido exterminada por los españoles, por los conquistadores de Colón: en treinta años murieron cerca de treinta millones de personas, de manera que cuando el Caribe fue heredado por lo que ha sido llamado el Nuevo Mundo, por el mundo moderno, no teníamos ancestros nativos. Teníamos en cambio una lengua impuesta, una política impuesta, una cultura impuesta que no me permitían, al caminar por la playa en Barbados, digamos, en 1960, en vísperas de la Independencia, tener un sentido natural, heredado, del génesis.

Esto hizo que mi anhelo de escribir acerca de los orígenes del Caribe fuera muy grande. A menos que yo pudiera escribir acerca de los orígenes de la situación geofísica natural en que me encontraba, no podría dar origen a mi propia poesía. De modo que hice rebotar mis guijarros sobre el océano, haciendo florecer nuestras islas que, en mi imaginación, se movían como ballenas en el horizonte. Pero no podía escribir el poema del génesis porque no tenía ni un modelo ni un sentido de la historia natural de nuestro archipiélago. Al intentar hacerlo, tropecé con incómodos modelos emanados del prejuicio, de la literatura, de la escuela. En lugar de escribir sobre 2.000 millas de islas, sólo lograba hacerlo sobre un pequeño charco a mis pies, pues estaba la influencia de John Keats, "Oda al charco, o charco solitario en el océano poderoso". O bien, si intentaba escribir el génesis de otra manera, se entrometía el poderoso Milton, se interponían estilos que no me permitían aprehender la esencia de nuestra historia.

$16 \quad 231 \mathrm{~km}^{2}$. 
Esto me impedía capturar la catástrofe a la que me referí. A través del pentámetro yámbico, que heredamos como colonizados y que estaba consagrado en nuestras escuelas, hice cosas como "vagué solitario como un... en colinas... narcisos... o días de despedida" y escribí maravillosos versos a lo Milton y a lo Shakespeare.

Pero el huracán que cada año rompe hacia el Caribe no ruge en pentámetros y no existe métrica inglesa para la niña esclava cuya espalda es destrozada por el látigo del amo cuando aúlla de dolor. A menos que pudiese encontrar algo que sonara como un fósil nativo, no podría escribir más que sobre charcos y cosas semejantes.

Entonces lancé al charco mis guijarros, pero seguí siendo incapaz de llegar a ningún lado hasta que, a partir de las piedras rebotando sobre el agua, tuve por primera vez un sentido visual: si Dios hubiese creado el Caribe, habría usado un guijarro, no un yunque ni un discóbolo, y cada una de estas piedras lo convertía, finalmente, en un dios caribeño. No habría usado ni una brocha, ni un lienzo, ni el techo de la Capilla Sixtina, como Miguel Ángel, ni tampoco una tormenta como Thor, Balder o Richard Strauss, sino un guijarro, y cada rebote de la piedra sobre el agua habría creado una isla, y así es como yo tenía a Cuba, Santo Domingo, Puerto Rico, las Islas Vírgenes, las islas Santas, Antigua, Montserrat, Martinica, Trinidad, Barbados. Al deslizarse sobre el agua, la piedra incluso creó la curva con su inercia y esto explica la forma curvada del Caribe.

Pero me seguía pareciendo que esa piedra no se deslizaba realmente, en mi mente, al ritmo de mi canción. Sólo fue al descubrir que el desliz de la piedra, esta síncopa puntillista, este inesperado movimiento de la piedra sobre el agua, era muy parecido en su forma ligeramente curvada a la cara de lo que habíamos creado en el Caribe y que llamábamos un steelpan ${ }^{17}$, que pude escribir el poema. Una de las invenciones originales del siglo veinte, el steelpan, constituye básicamente la música de Trinidad. Y con ese sentido de la mariposa, de Anansi ${ }^{18}$, del steelpan, del calipso, se me ocurrió que disponía -pese a que las escuelas no me permitían comprenderlo- de una canción antigua y muy moderna a la vez; de una canción que podía correlacionar con el desliz de la piedra sobre el agua, permitiéndome escribir aquel sencillo génesis caribeño. Si lograba establecer la relación con el sonido de la piedra deslizante, me sería posible encontrar mi propia

17 El steelpan, literalmente un "tambor de acero" o "tambor metálico", es un instrumento de percusión musical y designa, por extensión, el género musical al que éste da lugar. Preservo la expresión en inglés pues su uso se ha extendido en el idioma castellano.

18 "Anansi" en los cuentos criollos caribeños es la araña, muchas veces mezclada con humano, y simboliza la astucia popular. El vocablo es originario del África occidental selvática. Otro gran personaje de los cuentos africanos, esta vez en zona de sabana, es la liebre, la que también tiene presencia criolla. 
expresión. No sólo sería capaz de escribir el primer capítulo del génesis, sino también de iniciarme en la poesía del Caribe. Y así fue como este poema, que está en el corazón de mi concepto del lenguaje-nación en cuanto me permite relacionar la piedra deslizante a la canción del calipso, me liberó de Milton, del pentámetro, de Miguel Ángel y de cualquier otra cosa. Celebra los ritmos de nuestro propio pueblo porque permite entrar en la experiencia del ritmo. Es muy importante reconocer que cada ritmo, cada metáfora, cualquier cosa originaria es el símbolo silencioso de algo mucho más profundo, mucho más originario, que, al comenzar a relacionarte con él, te conduce al futuro de su realidad escrita.

Y así fue cómo comencé a escribir: "la piedra se deslizó arqueó y floreció hacia las islas, Cuba y Santo Domingo, Jamaica, Puerto Rico, Granada, Guadalupe, Bonaire". Así comienza este sencillo poema, ésta es la piedra deslizante. Pero, de hecho, aunque pueda parecer eso en la página, hay en él mucho más que sólo escritura, porque el lenguaje-nación es esencialmente una experiencia holística. El lenguaje-nación es una experiencia conectada al mismo tiempo a lo visual y a lo auditivo. El lenguaje-nación necesita tener movimiento en su interior. Ésta es su esencia. Es capaz de crear un cuadro total de la experiencia mediante un simple sonido. Es un poema que no está para ser dicho, sino para ser cantado. De manera que el primer poema que escribí suena parecido a esto:

\author{
La piedra se deslizó arqueó y floreció hacia \\ las islas: \\ Cuba y Santo Domingo \\ Jamaica y Puerto Rico \\ Granada Guadalupe Bonaire \\ la piedra curvada silbó hacia el arrecife \\ las olas dentadas desgarraron la arcilla \\ la espuma blanca destelló en rocío \\ Bathsheba Montego Bay
}

Florecer de los veranos que se arquean... (1973) $)^{19}$

Glissant: Fue muy interesante escuchar lo planteado por Brathwaite. Veo algunas diferencias, sin embargo, respecto a mi propia situación. Primero que nada, en mi país, Martinica, hay una lengua creole ${ }^{20}$. Existió

19 "The stone had skidded arc'd and bloomed into / islands: / Cuba and Santo Domingo / Jamaica and Puerto Rico / Grenada Guadeloupe Bonaire // curved stone hissed into reef/ wave teeth fanged into clay / white splash flashed into spray / Bathsheba Montego Bay // Bloom of the arcing summers... (1973)".

20 "Creole": criollo / criolla, es decir, lengua criolla. Al usar la expresión "creole" me refiero a esta lengua surgida en el Caribe. Mantengo la grafía anglófona y francófona (si bien en francés lleva un acento agudo en la primera "e": "créole"), aunque propongo pronunciar la palabra en español omitiendo la última "e": "creol". Otra grafía, en lengua creole, es por ejemplo "kweol". 
en Trinidad, en Jamaica y en Barbados bajo una variante anglófona, pero luego desapareció. En Martinica todavía tenemos un creole que es francófono porque, en el siglo diecisiete, los franceses ocuparon Martinica, así como Santa Lucía y Dominica. En estas islas se habla el mismo creole que en Martinica, pero la gente de Martinica llama ingleses a la de Santa Lucía y la de Santa Lucía llama franceses a la de Martinica, pese a que hablan el mismo creole. Cuando me encuentro con mi amigo Derek Walcott, hablamos creole porque es más fácil.

Una definición del creole es la de una lengua mezclada con elementos tomados de dos diferentes lenguas-madres. Esto significa que, en Martinica, Haití, Guadalupe, Santa Lucía o Dominica, el creole está hecho a partir de un léxico francés. Para decirlo con más precisión, no es el idioma francés; sino la lengua de Normandía y de Bretaña, la lengua hablada por los marineros y otros inmigrantes. La sintaxis es una suerte de sintaxis de varias lenguas de la costa occidental de África. El creole, por tanto, es realmente una lengua de mezcla, así como una lengua de compromiso entre los antiguos esclavos y los antiguos amos. El genio de nuestro pueblo es haber hecho de este compromiso una lengua real.

En general, es posible distinguir el creole del pidgin o de un dialecto. El pidgin o cualquier dialecto están hechos a partir de una lengua, pero no se encuentra la mixtura específica de un léxico occidental y de una sintaxis africana en ningún otro lugar, solamente en el Caribe. En mi opinión, aquí no hay solamente mestizaje. Es imposible predecir los resultados del acriollamiento ${ }^{21}$ porque es impredecible y esto es lo principal que debo señalar aquí: en el Caribe, la mezcla y el compromiso cultural son impredecibles.

Me impresionó escuchar a Brathwaite hablando acerca del Caribe porque, desde mi punto de vista, si quiere hacerse un paralelo entre el Caribe y el antiguo Mediterráneo, el viejo Mediterráneo, puede encontrarse que este último es un mar que concentra, que fuerza a la unidad del ser. Puede observarse que todas las religiones monoteístas nacieron en torno al Mediterráneo. Es allí donde nació la filosofía de "I'un"22, de la unidad, de lo uno. Y, si se mira al Caribe, se advierte que es un mar

21 El término original en inglés es "creolization", que en francés es "créolisation" y en castellano es "criollización". Aunque se trate de una operación riesgosa porque la noción de "poética de la criollización" está en cierta forma instituida, me aparto de la traducción literal para adoptar la versión de "acriollamiento" usada por los cubanos Emilio Rodríguez-Jorge y Nancy Morejón. Mientras que la noción de criollización evoca la idea de un proceso sin fin, de una interminable difracción, la de acriollamiento transmite mucho mejor el pensamiento orientado o convergente de Édouard Glissant hacia un lugar específico concebido como "punto de intrincación": las Antillas, en el Caribe, y éste en las Américas.

22 En francés en el original. 
que difracta. No que concentra, sino que difracta. El mar y las tierras no están alrededor de él, sino en su interior. Esto es algo que mis amigos en París no entienden. Ellos me preguntan: "¿Cómo puedes vivir en un país tan pequeño?". Piensan que me siento encerrado porque Martinica es una pequeña isla, pero no es así, porque Martinica no es un mundo que concentra; puedo pasar allí seis años sin ir a ninguna parte porque el genio del país es difractante, consiste en imaginar cosas que ocurren en cualquier otro lugar. Esta es la poética de lo que llamo el acriollamiento, una poética mezclada, impredecible y multilingüe.

Cuando escribí Le discours antillais ${ }^{23}$ ["El discurso antillano] (1981), selectivamente traducido como Caribbean discourse ${ }^{24}$ ["El discurso caribeño] (1989) al inglés, algunos jóvenes escritores de Martinica bien conocidos en el área tomaron tópicos de mi trabajo para desarrollar la teoría de la criollidad ["créolité"]. A partir de esto publicaron un libro, Éloge de la créolité ${ }^{25}$ [Elogio de la criollidad] (1989), en París, donde se refieren permanentemente a Le discours antillais como su fuente y raíz. Cuando me dieron el manuscrito, les dije que siguieran adelante. Pero una vez que el libro fue publicado, les señalé que no estaba de acuerdo con la teoría de la criollidad porque, para mí, el acriollamiento es un proceso que difracta. No pretendo proponer un modelo para la humanidad del modo en que lo han hecho para nosotros las culturas occidentales. Estamos en un proceso de acriollamiento. No somos una definición del ser criollo y esto marca una gran diferencia.

Hay un concepto contra el cual estoy peleando en relación al lugar que ocupan la filiación y a la legitimidad en las culturas occidentales. Estas culturas han desarrollado un concepto de transparencia de la humanidad al cual han de ajustarse todos los hombres y todas las mujeres del mundo. Algunos están cerca del modelo y otros están lejos de él. El problema de este concepto de transparencia es que toda la gente debe corresponder con su modelo. Pero hay algo más. El concepto del derecho a la diferencia ha sido muy fuerte en la lucha por la descolonización, pero no es suficiente. Yo quiero tener derecho a la opacidad, es decir, que no me sea necesario entender lo que soy, que pueda sorprenderme de mí mismo y aún así seguir haciendo cosas, trabajar y así sucesivamente.

23 Glissant, Édouard (1981). Le discours antillais. París: Gallimard. Traducido recientemente al castellano: Glissant, Édouard (2005). El discurso antillano. Trad. de Aura Marina Boadas y Amelia Hernández. Caracas: Monte Ávila.

24 Glissant, Édouard (1989). Caribbean discourse. Selected Essays / by Edouard Glissant: translated and with an introduction by J. Michael Dash. Charlottesville: University of Virginia.

25 Bernabé, Jean, Patrick Chamoiseau y Raphaël Confiant (1989). Éloge de la créolité. París: Gallimard. Un fragmento de esta obra está traducida al español como: Bernabé, Jean, Patrick Chamoiseau y Raphaël Confiant (1996). “Nos proclamamos 'créoles'”. En: López Morales, Laura, comp. Literatura francófona. II. América. México: FCE. 49-55. 
Cuando mencioné por primera vez este concepto de opacidad, hace unos seis años atrás, todo el mundo dijo "¡cómo puedes vivir con algo o alguien que no entiendes!", pero creo que este punto de vista es una trampa. El primer sentido de comprendre [comprender] ya es significativo. Porque comprendre significa prendre [tomar] e incluso tal vez estrangular. Esta es una típica actitud científica occidental, según la cual los países y las culturas como las de las Indias occidentales ${ }^{26}$ no podrían constituir ningún modelo para la humanidad. Sólo que yo no pienso que estemos únicamente encontrando un génesis en las Indias occidentales, es decir, un génesis de nuestra cultura, sino que además estamos volviendo a la narrativa. Estamos conquistando un futuro. Esto puede diferir un poco de lo señalado por Brathwaite pero, en general, estoy totalmente de acuerdo con lo que él planteó.

BRATHWAITE: Aunque me he encontrado con Glissant en varias ocasiones, ésta es la primera vez que hemos intercambiado opiniones. Estoy muy agradecido por ello porque, como lo dijo y lo confirmo, compartimos muchas ideas acerca de conceptos tales como el futuro, la transparencia y la opacidad. Por supuesto, yo lo planteo de otra manera, dado que provengo del Caribe anglófono y él de un área francófona. Pero lo que me entusiasma es que compartimos esta base común, que en cierto sentido constituye otro aspecto del lenguaje-nación. Aunque hemos estado separados por la distancia, el idioma y la política metropolitana, seguimos estando comunicados a través de esta interconexión. Estoy de acuerdo en cuanto a que no deben hacerse paralelismos. Yo solía decir que las culturas occidentales eran como misiles y Glissant hizo todos los movimientos de un misil. La otra cultura, la del lenguaje-nación, es la cápsula, la cosa que es acarreada por el misil en su desplazamiento por el espacio. La cápsula contiene sus fuerzas vitales auto-contenidas. Su paradigma no es el de cortarse las piernas, sino el de auto-contenerse, es decir, lo que él llamó la opacidad, el reclamo a la privacidad. Constituye por tanto un aserto de anti-conquista, se trata de una cultura que no está preocupada por adquirir o por reclamar las lenguas o las posesiones de otros pueblos. Es un sueño y una idea, pero pienso que debemos decirlo cada vez más, y lo más fuerte posible.

GLISSANT: Es interesante pensar, en este contexto, en el concepto de paisaje, aplicado tan a menudo como modelo de humanidad. Yo solía citar un trabajo de Ernst Robert Curtius, Literatura europea y Edad Media

26 En el mundo anglófono, la expresión "Indias occidentales" o "West Indies" designa los territorios americanos y, debido a la temprana emancipación de los EEUU, muy especialmente las posesiones coloniales británicas en el Caribe. Dentro del Commonwealth se les distingue de las "Indias orientales" o "East Indies", que son los territorios asiáticos y en particular la India. La expresión "Indias occidentales" no es muy recurrida en la francofonía y Glissant la ocupa porque se está dirigiendo a un auditorio inglés. 
latina (1948). Curtius señala que todos los parámetros de la literatura europea tienen un tópico que es el paisaje ideal, el del prado y la fuente. De acuerdo con este autor, los parámetros y la prosodia de todas las literaturas europeas tienen este tópico como base común. Me di cuenta de que en el caso del Caribe es diferente porque, en nuestra región, todas las literaturas hablan de la selva, de los terremotos o de las tormentas. ¡Ud. dijo lo mismo, Brathwaite, al hablar de la piedra deslizante en el mar! En la gran literatura europea, el paisaje es un decorado, un marco. Cuando un poeta o un novelista describen el paisaje, pueden hacerlo maravillosamente bien. Me gusta el paisaje en El lirio en el valle (1863), de Honoré de Balzac, y podría dar muchos otros ejemplos, pero en ellos siempre hay un decorado, no una parte interna. En nuestras literaturas, el paisaje no es un decorado, sino un personaje en sí mismo.

Tenemos dos variantes de paisaje. Primero, porque vinimos por mar, a través del Paso del Medio ${ }^{27}$, hacia las islas, y allí imaginamos el mar, como señaló Kamau. Y, junto con esto, estábamos en el período de la esclavitud. Al decir "esclavitud" pienso en los cimarrones que huyeron hacia el bosque, hacia las montañas, para liberarse. Por tanto, nuestras ideas de libertad están vinculadas a las montañas y al mar. Y la libertad debemos conseguirla entre ambos extremos, entre las montañas y el mar.

Estas ideas sobre la libertad nos condicionan de manera muy importante. Por ejemplo, cuando Fidel Castro estaba en la oposición, podría haberse ido a La Habana y vivir en la ciudad, pero en lugar de eso se fue a la Sierra Maestra. Por un lado, esto fue políticamente estúpido, dado que los soldados de Batista lo esperaban allí. Pero, por otro lado, es increíble lo típico que resulta estar en la Sierra Maestra para un cimarrón, es decir, se trató de acto propio de las Indias occidentales. La relación con el paisaje provino de una larga historia. Tal vez no lo sabía, pero el simbolismo de ese acto fue muy fuerte.

Está claro que nuestra relación con el paisaje es algo que no puede imaginarse si no se tienen en mente este tipo de imágenes. Cuando estaba en Martinica, podía observarlo en las casas. Está la cima; tradicionalmente, todas las casas de los amos estaban allí, porque es donde hay más aire fresco, y todas las casas de los esclavos se ubicaban más abajo, no sólo por el aire, sino también por los huracanes, porque toda la tierra desciende a las casas de los pobres. $Y$ ahora puede verse a los martiniqueños conquistando la cima, lo que sociológicamente es muy importante, pues

27 "Middle Passage". La expresión en inglés y con mayúsculas, desde que la acuñara V. S. Naipaul, se utiliza para designar la porción del océano Atlántico por donde transitaban los barcos negreros entre África y América, en el período histórico de la esclavitud (siglos XVI a XIX) y dentro del Ilamado "comercio triangular" que vinculaba estos continentes a Europa. 
esta relación significa que el estatus no cambia únicamente por hacerse rico y comprar una casa. Más importante que esto es la relación con el paisaje, que cambia; tú cambias. Yo no lo llamaría un modelo para la humanidad, sino más bien un modo de estar en el mundo.

Brathwaite: Quisiera agregar algo más. Nuestro paisaje es mucho más violento, cambia constantemente debido a la luz del sol, al terremoto, a la tormenta. En un sentido, uno debe retrotraerse a la situación previa para describir el paisaje. Permítame darle el ejemplo de mi propio poema "Flautas" ["Flutes"]. Hasta 1988 viví en las colinas en Jamaica, en un lugar llamado Irish Town, y había allí un boscaje de bambú. Cada año se acercaba más, así es que finalmente escribí un poema que yo consideraba el poema del bambú, "Flautas". Mi relación con aquel ramaje de bambú fue muy cercana hasta 1988, cuando el huracán Gilbert transformó ese lugar de dorado bambú en un sitio lúgubre, oscuro, catastrófico, dos veces más alto que mi casa. Todo lo que había tenido relación con el bambú se volvió oscuro y cataclísmico. El ejercicio de mi poesía se vio alterado y fue como si toda mi alma se hubiese derramado en este tipo de inmundicia. Existe una relación con el paisaje que está presente en las obras de muchos artistas caribeños.

Siendo una poesía de la luz y el destello, una poesía suave y esperanzada, ella se volvió muy oscura y sísmica. A partir de ese momento, se convirtió en una suerte de prosa, única manera de relacionarme con ese tipo de desastre en particular. Pero, como señaló Glissant, es imposible conformar un modelo a partir de esto, pues un modelo de 1986 es diferente en 1988. Ahora el bambú ha comenzado a retroceder nuevamente y pronto tendremos un paisaje criollo, un paisaje que nació siendo oscuro y catastrófico sin dejar de ser verde y esperanzador. Tendré que llegar a un equilibrio. Es sólo después de vivirlas que se disponen de expresiones suficientes para designar este tipo de experiencias, entonces la crítica comienza a destacar un denominador común; es lo que llaman teoría. Pero las expresiones de estas experiencias preceden a la teoría. Un artista caribeño no puede comenzar con una teoría, con un modelo; siempre debe empezar a partir de su relación con lo que está ahí.

Glissant: ¡Esto es muy importante! Tome por ejemplo nuestra relación con América Latina. En el siglo dieciséis, el mar Caribe era llamado "El Mar del Perú" y el Perú está al otro lado del continente, de modo que se llamaba así porque en esos tiempos debía atravesarse el Mar Caribe para llegar hasta allá. No había otras rutas para los conquistadores; pienso que esto es importante. Hay muchas Américas: América del Norte, América del Sur, América Central y las Indias occidentales o el Caribe. Esto de no tener filiación, de carecer de un vínculo con los orígenes, es igual para todos estos tipos de génesis. Sin embargo, al estudiar las culturas y las 
teologías de los mesoamericanos, encontré un concepto de génesis y de filiación muy interesante, consistente en un sistema de períodos cíclicos de 52 años. ¡O sea que hay un hoyo! ¡No hay génesis! Esto nunca se encontrará en un mito griego o en la religión cristiana, pues en ellos, cuando hay un hoyo, se decide que Matusalén vivió 900 años o que Noé vivió 700 años. Es necesario hacerlo de este modo para poder conquistar una legitimidad. En las culturas mesoamericanas no existe esta preocupación. Tampoco existe este tipo de vínculo en las culturas africanas. Se tienen filiaciones no por legitimidad, sino por adopción. Éste es el acriollamiento que está operando alrededor del mundo y que yo llamo la poética del acriollamiento.

Brathwaite: Es interesante que Glissant se refiera a Martinica como parte de América Latina. Es impensable que Jamaica y Barbados o Antigua o Saint Kitts alguna vez hayan soñado con América Latina. Ni siquiera saben lo que significa esa palabra. Nuestro concepto de historia del mundo es muy afro-sajón y protestante, pues es el producto de una sociedad inglesa muy extraña y materialista. Crecimos en el Caribe, donde solamente se conoce Londres o Australia o Canadá, es decir, cualquier cosa que sea vital para el imperio Británico. Pero nos estaba prácticamente prohibido involucrarnos con lo caribeño, fuese lo que fuese: nuestra propia música, nuestras propias expresiones en el lenguaje, en el lenguaje que hemos creado a lo largo de los años y, sobre todo, a partir de nuestro aislamiento del resto del Caribe.

Permítanme darles un ejemplo. Si yo hubiese vivido en la isla de Santa Lucía en el año 1.400 y hubiese querido visitar a Glissant en Martinica, podría haber ido al Morne ${ }^{28}$ sobre Castries y haberle enviado a él o a su tío una señal de humo, o bien haber usado un espejo para avisarle "Ilego esta tarde en una canoa". Nos habríamos adentrado en el mar en el momento correcto y, sin duda, habríamos llegado sanos y salvos a la playa. Hoy, si quiero visitar a Glissant desde Santa Lucía a Martinica, todo lo que debo hacer es tomar un crucero de Santa Lucía a Londres, luego cruzar el canal desde Londres hasta Calais y después tomar un crucero francés. Hasta el teléfono funciona de esta manera. Es que la distancia es parte del problema, no es un asunto solamente lingüístico o político; es parte de la totalidad de un sistema de compartimentalización (compartiMENTALización) de la comunicación. Y es particularmente el caso para el Caribe anglófono. En el caso de las islas francesas, han seguido vinculadas a Europa, de manera que tienen una salida hacia el mundo. En cierto modo, son parte de Francia, aún cuando su situación pueda ser incómoda. Las metrópolis jamás pensaron que nosotros merecíamos recibir educación, de modo que ésta tenía que

28 Pequeño poblado situado sobre Castries, capital de Santa Lucía. En el Caribe la palabra "morne" designa un monte. En francés "morne" significa también "oscuro" o "apagado". 
ser, en cierto sentido, ilegítima. Nos enseñamos a nosotros mismos, lo que fue extraordinario. El profesor no podía enseñarnos lo que queríamos que se nos enseñara, así es que nuestros padres pidieron que la escuela nos permitiera enseñarnos a nosotros mismos y también que tomáramos nuestros propios exámenes, que seguían siendo públicos. Al enseñarnos a nosotros mismos, descubrimos Harlem ${ }^{29}$ y a T. S. Elliot. Y al descubrir a Elliot descubrimos una voz poética moderna. Sin esto, habríamos caído en el pentámetro inglés, en los románticos ingleses, Uds. saben, en la actitud de Swinburne. En la escuela yo no tuve ningún tipo de contacto con un hombre llamado Nicolás Guillén. No sabía que Brasil tenía esclavos y que era una sociedad de plantación similar a las nuestras. Tampoco sabía que África existía y que era un gran lugar, aunque Barbados sea la más oriental de las islas caribeñas y que desde allí, en un día neblinoso, sea posible imaginar la costa de Guinea.

Al descubrir Harlem vimos la conexión de la voz poética moderna con la música, la relación de la música y la palabra en Louis Armstrong o Duke Ellington, por ejemplo. Se trataba de una total liberación del arte expresada en la música-palabra-danza. En otras palabras, nos dimos cuenta de que algunos de nosotros podíamos cantar, de que algunos de nosotros estábamos cantando incluso en otro país, aún cuando se nos había hecho entender que el canto no era bueno para nosotros. En ese entonces, el calipso estaba prohibido en Barbados. Los padres se disgustaban mucho si lo cantabas y nunca se le escuchaba en la radio. La gente pensaba que era una música del demonio, que sólo era la expresión de algún tipo abominable de personas. Y esto seguramente no era sólo el caso de Barbados, sino también el de otras islas.

En la enseñanza, sin embargo, estos conceptos de opacidad, transparencia y futuro siempre resultan engañosos. Yo trabajo en el Departamento de Historia, pero soy un poeta y opero como tal, así es que, si los estudiantes esperan tener lecciones de historia, sobre todo de historia económica, no las recibirán de mi parte. No he investigado en archivos buscando hacer una historia política y económica. Mi investigación siempre surge de las metáforas que descubro en mi poesía. Sólo ahora estamos descubriendo las áreas sumergidas del Caribe, las vidas de la gente y las instituciones que crearon durante el largo período de la esclavitud y la

29 El Ilamado "Renacimiento de Harlem", florecer artístico de la cultura negra que tuvo lugar en Nueva York a comienzos del siglo XX, acompañó el despertar de la conciencia negra en el Caribe y otros lugares, influenciando asimismo las vanguardias europeas y americanas. Su resultado más destacado es el jazz, como lo traslucen las palabras de Brathwaite, pero en él participaron asimismo escritores como Countee Cullen, Charles Mackay o Langston Hugues. Una traducción al español de algunos de los textos asociados al Renacimiento de Harlem se encuentra en: Pereda Valdés, Ildefonso (1936). Antología de la poesía negra americana. Santiago de Chile: Ercilla. Agradezco al estudiante de la UCSH Milton Carrasco el hallazgo y el préstamo de tan raro y valioso volumen. 
colonización. Una institución como "Landship"30, una organización de auto-ayuda en Barbados, por ejemplo, me inspira e incluye la noción de susu o coumbite, como puede encontrarse en Guadalupe y Haití.

Al escribir mi poema "La cabaña" ["The Cabin"], basado en una cabaña de esclavos en Jamaica, fui capaz de describirla porque pude verla. Pero al abrir su puerta, me di cuenta de que no sabía lo que había allí y que no conocía a la gente que estaba dentro. La única cabaña que conocía en ese momento era La cabaña del Tío Tom (1855), de Harriet Beecher Stowe, así es que, como historiador, tuve que hacer la investigación necesaria para descubrir qué es lo que hacían los esclavos jamaicanos en ese momento, qué se les exigía que hicieran y qué tipo de amoblado mental y físico formaba parte de su mundo. Éste es el tipo de investigación que yo realizo, siempre surge de una metáfora, de un poema que permanecía irresuelto debido a la ignorancia. Cualquier intento por descubrir algo del Caribe se ha basado primero en un salto imaginativo hacia lo desconocido y, después, en un esfuerzo historiográfico, archivístico, para entenderlo y definirlo. Y yo diría que ocurre lo mismo en cualquier parte del mundo, sólo que en el Caribe nuestros recursos son tan ricos y a la vez tan poco explotados, incluso tan poco explorados, que eso debe necesariamente llevarse a cabo.

Por tanto, esta aproximación multidisciplinaria es fundamental en el Caribe. Cualquier cosa a la que uno se aproxime tiene una multiplicidad de connotaciones, de matices, de implicaciones en muchos niveles. Aprendí esto por accidente. Estudié historia en la Universidad de Cambridge, donde tuve que elegir entre literatura e historia. Me incliné por la historia porque sentía que sería más difícil, puesto que la literatura ya estaba conmigo. Al partir de Cambridge, escapé de la historia por muchos años, como esperaba hacerlo. Mientras vivía en la isla de Santa Lucía, en cierto modo escondiéndome en ella, fui descubierto por un historiador, un académico de la Universidad de West Indies. Le pareció que era una desgracia para un historiador, para hombre de Cambridge, como decía él, permanecer oculto de este modo. Y planificaron mi regreso a Jamaica, lo que ocurrió hace cerca de veinte años atrás. No es necesario decir que los académicos, mis colegas profesionales, difícilmente me hablaban en el Departamento de Historia. No entendían cómo funcionaba esta cuestión, pero ahora han aceptado que funciona. Y gracias a nuestros esfuerzos, la historia cultural y social está pasando a tener un lugar fundamental en la Universidad de West Indies. Ahora todo el mundo está haciendo historia social y cultural.

Es muy importante, incluso como académico, tener tu propia biografía, tu propia autobiografía, saber cómo alcanzaste tal conclusión a

30 "Navetierra". 
partir de tu propia experiencia. Y esto es lo que siempre intento hacer. No estamos separando la palabra de la esencia, para nosotros la palabra y el mundo siguen siendo contiguos, mientras que en muchas otras disciplinas y sociedades, a partir del Renacimiento, la palabra y el mundo han evolucionado de manera separada. Yo todavía estoy "descubriendo" el Caribe, así es que no tengo la sensación de estar "inventando" algo. ¡En cualquier caso, es el Caribe el que me está inventando a mí! Es el Caribe el que me ha transformado cada vez más a medida que he dedicado mis esfuerzos a trabajar en el área. Y debo usar una palabra como "esfuerzo", Uds. saben, debido a que los británicos, anglófonos y protestantes -desde luego-, aunque sean similares a nosotros, hicieron nuestra historia colonial. Nos cortaron del resto del Caribe.

GLISSANT: Mi experiencia proviene de la plantación en la que nací. Mi padre era una especie de capataz y viajaba de lugar en lugar, así es que pude conocer bastante bien todos los aspectos de las culturas de Martinica. Durante mi infancia escuché los cuentos criollos y la música en el campo. Es por esto que necesito intelectualizar todas aquellas experiencias en lugar de volcarme hacia la esencia. Es una diferencia con algunos de mis camaradas escritores en la Martinica de hoy, jóvenes escritores que viven en las ciudades y no conocen la vida de la plantación. De manera que tengo una tendencia a considerar una suerte de ser total en el mundo, enfatizando no sólo la esencia -no me gusta esta palabra-, sino también la comprensión intelectual de las cosas, mitad y mitad. Tal vez sea pre-socrático, ciertamente no heideggeriano. Siento una gran predilección por los pre-socráticos porque no creo que haya sido en el Renacimiento cuando los hombres se separaron del mundo, sino que desde Sócrates y Platón. Tal vez los pre-socráticos eran hombres negros en sus corazones. No formaban parte de la cultura occidental. Eran algo más que se ha perdido y que tal vez debamos reencontrar.

Lo otro es que, al escuchar a Brathwaite, pensaba en las Indias Occidentales francófonas. Tenemos la mejor y la peor de las partes. La mejor porque tenemos acceso al conocimiento, pero sin la actitud que hay en las Indias Occidentales anglo o hispano-hablantes. Siempre me sorprendieron (mientras trabajaba en la UNESCO) los conflictos entre mis amigos de Jamaica y Trinidad y Barbados y Santo Domingo y Cuba. Siempre había algún conflicto. Había una mujer de Trinidad, muy inteligente, que decía: "Trinidad es una potencia atlántica". Y yo le preguntaba: ¿¿De qué está hablando, qué es eso?". Y los indo-occidentales anglófonos decían: "Ustedes, los de Cuba, intentan colonizarnos"; y así sucesivamente. Pero estos puntos de discusión me resultan paradójicos. Tal vez tengamos la oportunidad de acercarnos más a los latinoamericanos y a los anglófonos, de manera de poder formar una especie de liga. 
Entonces, los indo-occidentales francófonos tuvimos acceso al conocimiento, lo que fue bueno. Lo malo es que esto significó que fuéramos asimilados. La colonización inglesa es ciertamente mala, porque el inglés no puede considerar que un trinitense o un barbadense sean realmente ciudadanos ingleses. Pero al hacerlo, en cierto modo, el inglés respeta la otra cultura. No hace nada en su favor, pero tampoco la toca, no la contamina. Cuando fui a Dominica no pude creer lo que veía. El inglés no había hecho nada, ninguna carretera, ninguna casa, nada de nada. Los franceses en Martinica nos dieron carreteras, electricidad, teléfonos, pero fuimos contaminados en nuestras mentes debido a esta asimilación por su cultura, de manera que los anglófonos y los hispanohablantes en las Indias Occidentales están más cercanos a su "esencia", es decir, a su relación con ellos mismos, que los francófonos.

Recuerdo algo que los cubanos me contaron hace mucho tiempo atrás. Estaba discutiendo con algunos líderes en Cuba y en ese momento ellos solamente tenían una palabra en mente: "América Latina"31. Yo les respondí, "okay, 'América Latina'", pero Uds. son indo-occidentales y, si no lo son, su ser-"América Latina" es falso, no es real, sino retórico. Y recuerdo que no entendieron lo que les estaba diciendo. Para ellos, en ese momento, las Indias Occidentales no eran nada y les tomó quince años entender que era imposible ser "América Latina" sin ser indo-occidentales. Al finalizar la discusión, me sorprendió que me dijeran: “Uds. los de Martinica y Guadalupe son más precisos de mente porque son los más frágiles y amenazados". Y me pareció que éste es el verdadero punto de la situación de las Indias Occidentales en relación a los francófonos, los anglófonos o los hispanohablantes. Mi conclusión es que no hacemos lo suficiente por converger. Tal vez esto suceda por la fuerza de la historia.

BRATHWAItE: Bueno, la primera convergencia debiera ser política. Las Indias occidentales británicas estuvieron planificando una unión política durante mucho tiempo, pero jamás incluyeron en su visión a los franceses o a los españoles. Pienso que esto tendría que ser lo primero. Lo otro sería realizar congresos culturales y romper la barrera comunicativa de las lenguas asegurándonos de que los escolares aprendan todas las que se ocupan en el Caribe. Carecemos de una lengua unificadora que pueda facilitar la comunicación en todos los niveles. Esto coincidiría con una estructura política común. Difícilmente habría conocido a Glissant en el Caribe. No hay relación entre la Universidad de West Indies y las universidades de Martinica y Guadalupe. De vez en cuando enviamos a nuestros estudiantes al extranjero y tenemos intercambios, pero éstos se organizan con muy poco entusiasmo y no es posible llevarlos a cabo

$31 \quad$ En castellano en el original. 
por cuenta propia, porque se quemarían todas las energías en el intento y la cosa se transformaría en una especie de cruzada. Además, dudo que estas iniciativas tengan algún tipo de continuidad mientras siga habiendo tan poco contacto entre las estructuras.

Por supuesto, tenemos un vínculo natural, África. Siempre que nos encontramos en los festivales o en cualquier otro lugar, reconocemos esta "mismidad" ["sameness"] en muchos aspectos, pero ella no ha sido utilizada como fuerza unificadora porque, en el Caribe, África sigue siendo un tema sobre el cual no se habla. Hay dos razones que lo explican: la buena es que no sabemos nada de África - ésta es la buena. La mala es que, cuando lo hacemos, ¡los demás grupos étnicos del Caribe protestan chiflando! Por ejemplo, el juego del críquet, ese gran juego que tenemos. Nuestro capitán dijo hace pocos años atrás que habíamos ganado una serie gracias al excelente juego de un joven (caribeño) "africano" [de aspecto africano] que estaba en el equipo. La gente nunca lo perdonó y cuando varios años después fue a Guyana, donde el $70 \%$ de la población tiene herencia india [de la India], fue abucheado. Sólo por esa declaración. De modo que África no puede ser utilizada como fuerza unificadora. Los amerindios tal vez podrían ser una mejor base, pero aquí, nuevamente, nuestra ignorancia de los amerindios es incluso mayor que la de los africanos. Nuestra ignorancia del pasado es atemorizadora.

GLISSANT: Esto puede ser verdad pero, en mi opinión, la dificultad es que somos prisioneros de nuestra propia concepción de la identidad. Pienso que la cultura occidental, en particular, fue la que nos metió en esto. La identidad como concepto se desarrolló en las culturas occidentales con el fin de conquistar el mundo. Tenemos que definir otro concepto de identidad que no esté ligado al concepto de la raíz, pues éste excluye al otro por motivos de guerra, de conquista o de intolerancia. Lo digo porque tengo la experiencia personal de las luchas políticas en mi propio país, así como la visión de las luchas políticas en otros países, como Argelia, por ejemplo. Y cada vez que he visto esta intolerancia, me he dado cuenta de que el resultado no sería el que esperábamos y que una vez más surgirían la intolerancia, el racismo, el anti-feminismo, el fundamentalismo o el anti-fundamentalismo religioso. Debemos intentar definir otro tipo de identidad, no el del enraizamiento seccionado, sino el de una relación que se teje como una red $^{32}$.

32 Siguiendo a la chilena Ana María Baeza, ocupo la expresión "una relación que se teje como una red" en lugar de la traducción literal de la oración, que sería "una relación a través de una red". Ver: Baeza, Ana María (2005). "Bolero, memoria, y el Loco afán en obras de Pedro Lemebel y Luis Rafael Sánchez". En: Phaf Rheinberger, ed. Memorias de la fragmentación. Tierra de libertad y paisajes del Caribe. Berlín: WVB. 75-96. 
En América Latina y en las Indias Occidentales hay una serie de niveles que se contradicen entre sí. Está la construcción de la nación, la que se contradice con la lucha de clases, y ambas definen la identidad colectiva y comunitaria. Hay cinco o seis comunidades étnicas diferentes y, cuando una nación intenta construirse, una de estas comunidades puede decir que lo está haciendo sobre sus hombros. Entonces están todas estas contradicciones, especialmente en América Latina, ¿pero cómo podremos vivir en comunidad mientras sigamos propagando la idea de que el ser humano sólo encuentra su identidad en las raíces? Yo, por ejemplo, vengo de una plantación, así es que sé lo que eso, pero eso no es todo lo que soy. Mi identidad no es solamente la cabaña donde nací, el cañaveral donde crecí. Conozco eso, está dentro de mí. Como persona, no necesito retrotraerme a eso todo el tiempo. Sólo es necesario hacerlo como colectividad. Porque eso fue cortado de nuestra memoria y debemos recuperar esta historia. Si los indo-occidentales y los latinoamericanos no intentan hacerlo, serán aplastados por fuerzas externas. Sea como sea, no es la forma de cambiar la mente de la humanidad. Las construcciones identitarias basadas en la raíz no son suficientes. Según entiendo el concepto de la poética del acriollamiento, debemos luchar contra cualquier tipo de mono-algo. Si defiendo mi lengua materna creole, no es sobre la base de una mono-lengua. Defiendo mi propia lengua porque pienso que, si ella desaparece, morirá algo que es propio de la imaginación del hombre. Y no pienso solamente en mi lengua. Cada año muere una lengua en África y esto es increíble. Una de las políticas que pueden seguirse para vencer al tiempo es luchar contra el mono-algo, el mono-legalismo, la mono-concepción del estado-nación, el concepto de raza, etc. Y si luchamos por la multiplicidad y nuestra lucha resulta exitosa en esta vida, entonces también lo será en otras vidas después de nosotros. Este concepto de multiplicidad no se opone al concepto de unidad. Pienso incluso que, mientras más se considera la multiplicidad, más es posible alcanzar la unidad.

Éste es mi primer punto. El segundo es que el poderío político, militar o económico está evidentemente del lado del concepto de identidad que denuncio. Pero la historia es impredecible. ¡No se sabe si en veinte o diez años más la economía aquí en los Estados Unidos o bien en el Japón se derrumbará! ¡No se sabe lo que va a pasar! Si alguien, hace un año atrás, hubiese dicho que el imperio soviético estaba por caer, se habrían reído de él y habría parecido imposible. No es posible predecir lo que sucederá en las relaciones internacionales, como no es tampoco posible fiarse de las acciones concretas que se lleven a cabo en la materia.

BRATHWAITE: Sus preocupaciones me parecen notablemente políticas e intelectuales. Ud. señaló que un estado-nación puede caer. Yo quisiera señalar otra cosa. De hecho, me interesaba lo que considero la 
divergencia de preocupaciones propia de la poesía, la que, espero, es capaz de subvertir al estado-nación desde dentro. Si no puede hacerlo, ¡¿entonces qué estamos haciendo sentados aquí?! Porque significa que somos completamente inútiles si no tenemos ningún sueño utópico, si no creemos real y fundamentalmente que un estado-nación es parte de nosotros y que podemos influenciarlo de alguna manera. O sea que la cuestión depende de la definición que tengamos del estado-nación, del modo en que concebimos sus extraños aparatos de funcionamiento. ¿Tenemos algún estado-nación? ¿Podemos cambiarlo como intelectuales o poetas? Yo diría que, si es que efectivamente podemos hacerlo, deseo leer poesía, y un tipo de poesía que tenga un fuerte impacto rítmico. En mi caso, el ritmo se hace mucho más evidente cuando la poesía toma vuelo y aparecen la síncopa, la cesura y así sucesivamente.

En cualquier obra caribeña el ritmo responde de la manera lo más cercana posible al ritmo primordial del paisaje, a un verdadero juego de rayuela del paisaje. Éste crea el ritmo con el cual se tiene que vivir, el ritmo que se observa y que se ve, el ritmo con el que se sueña. Entonces el abrupto cambio de estaciones constituiría otro ritmo, además, por supuesto, del mismo ritmo de la gente, de la forma en que caminan, en que hablan en los mercados, la violencia repentina seguida de las risas, el constante signo de un vacuno muerto en las calles cuyo cadáver tiene la señal de una mariposa. Estos son ritmos que forman buena parte de nuestras vidas, porque la mariposa está chupando algo de la sangre que está creando un signo de amor sobre ese destino, cuando se tiene una forma que contrapone dos conflictos. Y me parece que el estadonación podría ser la vaca, que el estado-nación podría ser ese cadáver, y que deberíamos crear el signo, que es en cierto modo la señal de una posibilidad de metamorfosis.

GLISSANT: Volvemos entonces al inicio de esta discusión sobre el lenguaje-nación, su cosmos-lengua y sus ritmos. Toda la música nacida en las Indias Occidentales, los gospels, el blues, la biguine, el calando, nacieron del silencio. Porque estaba prohibido hablar fuerte y cantar. Nació del silencio y en el silencio. Uno de los aspectos culturales de la música que resultan comunes a todas las áreas de plantación en las Américas fue la necesidad de cantar sin ser escuchado por nadie más, trátese del amo o de cualquier otra persona. El arte del silencio es fundamental en este tipo de música. Y cuando la música estalla en sonidos, sigue estando presente en estos estallidos, en este tipo de arte del silencio. Él le da la síncopa a esta música. Por tanto, estas preocupaciones políticas e intelectuales en cierto modo son incorporadas en sus ritmos, con "lo impredecible de su síncopa puntillista y de su inesperado movimiento", tal como lo explicó Brathwaite y dentro de lo que yo llamo nuestra poética del acriollamiento. 